\title{
The exercise of the object
}

\section{Charles Travis ${ }^{1}$}

Published online: 13 November 2019

(C) The Author(s) 2019

\begin{abstract}
What is an object? A prior question: What is objecthood? Au fond, and to logic's eye, object is a role to be played with respect to a thought (on a decomposition). It is to be a countable which that thought represent as being some way for such a countable to be; what restores the business of truth-of to that of truth outright. What plays that role for some given thought is then an object with respect to that thought. Given this, there are corresponding absolute notions, to be fit for this role, and to be fit only for this role. So the fundamental task here is identifying the conditions on playing this role at all. All this is a contribution, however limited, to a topic called 'ontology'. This last word also occurs in the plural in several contexts. The end of this essay considers how these notions (non-countable, and the several countables) might relate, and what assumptions underlie what some have seen them to.
\end{abstract}

Keywords Objectivity · Environmental (spatiotemporal) $\cdot$ Exteral $\cdot$ Frege $\cdot$ Objecthood Ontology · Quine

Three questions: What is an object? What objects are there? What is (an) ontology? ${ }^{1}$ The first may mislead. For it may seem to call for an answer of the form, something is an object iff it satisfies condition C. But then, suppose something fails $\mathrm{C}$. What is it then? Chopped liver? The issue here can also be put another way: the question treats object as a categorial notion, marking off some class of things, 'the objects'. An assumption worthy of critical examination, this, though, pending an alternative sort of notion for object to be. A better question: What is objecthood? Such will be central here.

'What objects are there?' presupposes some definite totality, 'the objects', the population of some determinate domain. But, for several reasons, there is and can be

${ }^{1}$ I thank David Zapero for saving me from several grave sins of omission and of commission.

Charles Travis

c.s.travis@gmail.com

1 King's College London, Institute of Philosophy University of Porto, Rua Maria do Carmo Freire 181, 4455-164 Lavra, Portugal 
no such domain. It is worth recalling here Frege's observation in Grundlagen (1884): it may be an intelligible question how many macadamia nuts there are in that mélange in the bowl, but not an intelligible question how many objects there are in the bowl, or the room, or my pocket. Object (the concept) comes with no principle of counting, as one would expect if it is the most general notion under which any sort of object falls. Might there be a unique way of counting types of object? Such, too, is doubtful.

Which brings us to our third question. One might say: an ontology is precisely such a catalogue of types. But the term is sometimes treated as personalised, or at least communitarian. One admits, or refuses to admit, things into his ontology. Or we do into ours. What could this mean? There are people I would admit to my home, others I would refuse to. Whatever policy I follow here (if any), it has no bearing on what people there are, or on where or when there would be one. Could personalised ontology be any different? My policy has some bearing on who satisfies the concept to be admissible by Travis to his home. So I can shape the extension of that concept by adopting a policy. To shape an ontology in this way, it would seem, one would need weapons of mass extermination or creation, not the (usual) tools of a philosopher.

All of which will, no doubt, seem merely bloody minded to practitioners of such esoterica. But the idea of personalising points to something. In 1893 Frege wrote of his then-favourite bête noir, Benno Erdmann,

I recognise a domain of what is objective and non-causal, whereas the psychological logician takes the non-causal straightaway as subjective. And yet there is no explaining why what has an existence independent of a judger must be wirklich, that is, capable of affecting the senses either immediately or mediately. No such connection between concepts is to be discovered. (1893: xviii).

Frege's psychological philosopher presupposes a dichotomy: what one cannot collide with, or, more generally, what we cannot act on or be acted on by, must be 'all in the head', this in one of its two senses: a psychological phenomenon, i.e., something for empirical psychology, or, more colloquially, 'just in the head' i.e., imaginary. Against this Frege (vide 1918: 69) posited a 'third realm', inhabited by what is as objective as 'Dinge' (in the first instance collidables), but, 'like Vorstellungen', he tells us, not objects of perceptual awareness (nor wirksam, that is, nodes in causal networks). This strand in his thought, among the most important ones, has proven also among the most difficult for philosophers to swallow, as has his separation of the logical from the psychological.

The deepest root of resistance to this idea of a third realm is a certain understanding of the notion objective, or objectivity. There will be more to say in what follows about such motive force. Initially, though, we can at least note a point of grammar, missing which may stand in Erdmann's way. In English the verb 'think' nominalises into a noun 'thought' in two different ways (into two different nouns): thought may be the worldly phenomenon of thinking, that of the doing of what thinkers do, or it may be (again still a mass) the object of thinking, what might be thought-e.g., 'current thought on hydroponics'. So, too, I think, 'Denken'. Thinking may certainly class as psychological. Its object, what may be thought, is not. It falls on the logical side of Frege's psychological-logical distinction. Where (but only where) needed, I will subscript: ' $\Psi$ ' for the psychological, ' $\Lambda$ ' for the logical. 'Gedanke', a countable, not a mass, articulates thought ${ }_{\Lambda}$ ). 
When we hear the word 'object', we are naturally inclined to think of something one can kick, a 'collidable' to coin a term, something with spatiotemporal location. If, with Erdmann, we rule out the idea of a third realm, the reach of the notion object cannot extend much farther. But suppose, in the nature of objecthood, a third realm is to be recognised. Then things change. The notion object immediately reaches far beyond collidables. Being wirksam in present sense now has nothing essential to do with objecthood. Now to be an item is simply to play a certain role in the business of being true - not holding true, but simply being so. The first step is then to consider just what business this is. Here I begin with that first step; the first step, too, to seeing what mandates a third realm.

\section{The Road to Objecthood}

The first stop on Frege's road to objecthood is what he calls a thought (a countable): what poses a determinate question of truth outright, or, as he puts it, 'that by which truth can come into question at all'. $(1918,1919)$. The other notions we will need are that of a proper predicative subthought, and that of a concept. Along this road the thought has both logical and ontological priority. All else is to be understood in terms of

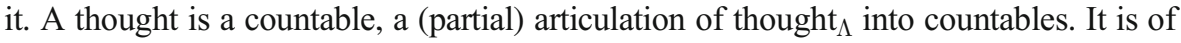
the way things are (a mass) as some given way there is for this to be. (In thinking a thought one eo ipso thinks it of - hence thinks of - that mass, the way things are. But one cannot think this to be, or even as being, so. One cannot think-that a mass.)

So the relevant articulation starts just here: an articulation of the way things are into particular, countable, ways things are. One might think: the articulation comes first: the way things are just consists in things being all the ways things are. The way with that idea is obviously not through a counterexample. It does, though, get its priorities backwards, in a way which begins to emerge below when we discuss the role of generality in representing. To adumbrate, in matters of logical and ontological priority one should take seriously Frege's remark,

A concept ... requires something which might fall under it; thus it cannot exist of its own accord. (1882: 118)

$A$ thought is identified by its proprietary form of engagement in representing-as (representing something as being something). It is a countable something there is (for a thinker to relate to in his representing-as. It is this phenomenon, representing-as, which first makes room for the notion to be true. Such room lies in the contrast between representing-as and factive representing (as where the flat tire represents (the effects of) contact with the sharp kerb). Absent such contact, what we get is not representing falsely; rather no representing at all. Representing-as is always susceptible still to have been done even were things not the way they are thus represented. Such even if the way it represents things is a way things could not but be. Such is internal to the way, not to the possibility of so representing things.

The business of being true is essentially tied up with generality. Representing-as, eo ipso, makes generality arise. Things are represented as such-and-such way-some 
given way for things to be. But, in the nature of the move from mass to count, being that way does not exhaust the whole. For all that things were that way, there is indefinite variation in how else they might yet be. The thought's task is to sort between what such variation is still permitted and what is now ruled out. There is indefinitely much here for a thought to decide. Just here its intrinsic generality.

Any thought is of that same mass) - the way things are - that this is some way there is for it to be. Just so its fitness for truth outright. Otherwise, given the thought it would remain to say what it was to be true of. Truth could then not be outright. The thought inherits its generality from that of this (countable) way for things to be. The countable is a partial articulation of the mass, what all truth outright turns on. Its generality consists in that which remains for articulation when so much (this way for things to be) has been hived off. What remains is always indefinitely much.

Frege insists that thoughts are 'invisible', that is, not objects of sensory awareness. We now see why. A given thought is distinguished from any other solely by its proprietary way of making truth turn on how things are. If, e.g., a thought were coloured, or of some given shape, or had a distinctive sound, such would not as such contribute to deciding whether what it represented as thus and so were, or were not, as represented. Its being square, for example, mandates no particular generality. Such rules out colour, and much else as well, as individuating features of a thought.

A thought can have no spatiotemporal location; hence it cannot contain indexical or demonstrative elements. A thought is not sentence-like: an artefact of the fact that it has a very different function from a sentence. One utters a sentence so as to make recognisable what thought he is expressing ('thought' here the $\Lambda$-mass). A thought is an identity for that which is expressed to bear: it identifies a given thing for thoughtexpression to accomplish. A thought is un-sentence-like in further ways, soon to come. But already the need for a third realm emerges.

The business of being true must bear being conceived as an exclusively two-party enterprise. Call this truth's austerity. In biblical terms, party of the first part proposes, party of the second disposes. Party of the first part will have to be some determinate countable instance of representing-as - of just 'that by which truth can come into question at all'; which is to say, a thought (Gedanke). Party of the second is the way things are. The work of party of the first is to impose a demand on being true. It answers the question how party of the second is to dispose: when so as to yield truth, when falsehood. Objectivity prohibits substantial contribution to this yield from any third part. A third party, the idea is, would make for relativity: truth relative to its contribution. The hallmark of truth, objectivity, would thus be lost. Thinking with Erdmann ('what one cannot collide with must be all in the head'), a third realm might seem a den of such third parties. But there is no need to think with him.

We might see party of the first (how something is represented being) as standing on the right-side of the representing-as relation, and party of the second (that which is so represented by the whole thought) as standing on the left. So speaking (and still restricting attention to the whole-thought case), we see that what stands on the left is absolutely unfit for service on the right; and is so just by dint of what fits it for left-side service. For what stands on the left is a mass yet to be articulated; what stands on the right is a potential articulation of it. What stands on the left is innocent of generality; what stands on the right is precisely to be individuated by its proprietary generality. What stands on the right is called on to answer questions when what was on the left 
side would be as represented, would instance the relevant generality (its). If the thought, e. g., is that Pia and Sid just popped another cork, when would it be a cork they just popped? What stands on the left is impotent here, has no answers to any such questions. That which is to count, or not, as a cork just popped cannot decide for itself when it will so count. Note, finally, that what stands on the right, what does the work as such of being true or false, is not to be found in our cohabited environment.

On the left, then, something representationally inert, something devoid of generality; in Frege 1983 terms, 'a particular case':

A thought always contains something which reaches over and beyond the particular case by which this is presented to consciousness as falling under some given generality. (1983: 189 (Kernsatz 4))

A reminder: so far we are considering only how truth outright is made to turn on that mass, the way things are (or things so being). When, later, we come to truth-of (of Sid, e.g., that he shuns asparagus), a complication enters. But we will deal with this when it arrives.

We have now come to a second reason for seeing the thought as something which is invisible, and ineligible to fill nodes in causal networks. Generalising (as a thought does) is not something one can watch. One can only grasp it. Sid overgeneralising as usual after his third may be a sight. A thought does not so perform in being of what such-and-such would be a case of. For a start, a thought is not the kind of thing which might take stances. It is rather of a way for things to be, identified by when that way would be instanced (a way things were). The point of Frege's third realm thus begins to become apparent.

In Frege's imagery one grasps a thought. Apt imagery, Frege tells us, thus far: one cannot grasp what is not there anyway to be grasped. One cannot grasp a non-existent pencil. But, he also tells us,

When I grasp a pencil many things happen in my body: excitation of nerves, alterations in tension and pressure of muscles, tendons and bones, alterations in blood circulation. But the totality of these occurrences neither is the pencil nor produces it. (1893: xxiv)

A thought is not an enabling device. To grasp a thought is to be sensitive, responsive, to a way for things to be - that way which the thought represents things being. But the thought does not enable such sensitivity as a hand rail in the underground enables one to remain upright. Rather, the other way around, such responsiveness is what earns one title to grasping it.

\section{Concepts}

One kind of rice may feed a hundred kinds of philosopher. But no one notion concept can be so bountiful. I mean the notion I will now introduce to be the most fit for present purpose. To introduce it a short detour will be needed. The next station on our route, then will be the idea of a proper predicative subthought. 
Central to logic as Frege conceives it is the notion of truth-preservation. Logic's business, he tells us, is to identify those transitions from a set of thoughts to a thought which are truth-preserving purely by virtue of what being true is as such. As Frege also notes, there is not that which the laws of truth might govern unless whole thoughts are decomposable into proper parts. What would a decomposition be? The answer is: the business of a whole thought is to make truth turn in a determinate way on how things are. A proper thought-part would be a partial doing of what the whole thought thus does (or, if you prefer, that which so does). There is such a decomposition just where those proper thought-parts which are its elements jointly do precisely what the whole thought they decompose thus does.

Which means that in principle a thought is decomposable in different ways into different sets of elements. Such is Frege's view. The contrast with sentences now deepens. A sentence is identified by its shape: a given structuring of given elements. Such suits it to thought-expression. A sentence thus has its proprietary syntax: for it to have an instance is for that instance to be so structured. A thought has occurrences, not instances. But it has a structure only relative to a way of decomposing it. (Whole thoughts first.) So for no structure would the thought occur only where so structured. Correlatively, a syntax may generate all those structures which are sentences of a given language. There is no hope of generating a corpus of what are 'the thoughts'. A thought is structurable only in terms of partial doings of what it does: making truth turn on how things are. This and its consequences, e.g., that there is nothing a thought looks like, reflect its mission just as having a syntax reflects a sentence's very different one.

There are, though, for Frege, types of subthoughts which are fundamental, at least for logic. Notably, he holds, any decomposition contains at least one element in the same business as the whole thought itself, to wit, that of representing-as. The idea would be: a decomposition must distribute the thought's work throughout the parts. The feature of representing something as being something is one thing to be distributed. In any given decomposition at least one thing must pick this up, to do which is to represent $a$ thing (or n-tuple) as some way for it to be.

Let us call an element which so engaged a proper predicative subthought. What it represented as thus and so could not be that on which truth outright always turns, or the subthought would not be proper. But it had better be something which makes this subthought's work, in the context of the decomposition, add up to the whole thought's work. What I want to stress at this point is just the logical and ontological priority of the whole thought. Subthoughts - so far predicative ones, but any — need to be defined, or understood, in terms of the whole thought. A proper subthought (e.g., a predicative one) just is what would add up to the (or a) whole thought in the right sort of decomposition containing it.

Concepts are now but a step away. The idea is as follows. Any two proper predicative subthoughts share something in common and (trivially) differ by something. What they share in common is being predicative subthoughts: so engaging in representing-as. What they differ by might be thought of as their content. Their common feature is: each represents something a some way for it to be. What they differ by must then be what this something is. One might call this their respective contents. Prescinding from their common feature and retaining only their differences, we arrive at our present notion concept. To repeat, such is not the only notion abroad in the trade. It is not even Frege's mature (post-1891) notion. But it serves present 
purpose. On it, there is a concept wherever there is a way for something, for a thing, to be, and vice-versa. A concept is of exactly one given such way. It is intrinsic to it to be so: to be it is per se to be of that. (By which this notion is distinguished from Frege's of post-1891.)

A distinction not needed in the case of truth outright now becomes crucial. Suppose a concept is of being F. Then we will say whatever is F, whatever is that which the concept is of being, to fall under the concept. In general whether something falls under a concept depends on how it is. Its being as it is may, or may not be, a (particular) case of something being that which the concept is a concept of. Where an item falls under a concept, I will say: its being as it is instances the concept. In the case of what any whole thought represents as some way, thus of ways for things to be, the distinction does little crucial work. Things, the mass, are such that Sid imbibes. One could speak of things being as they are as falling under the concept things being such that Sid imbibes. But then it would still be things being as they are which was a case of, so instanced, this. Had Pia favoured trainers over mules things being as they then would have been would be a different case. By contrast, for proper predicative subthoughts falling under and being instanced are not the same things, nor done by the same things. What instances is the invariable first locus of generality. But such is peripheral to present purpose.

Following Frege I have spoken of concepts as intrinsically of a way for $a$ thing to be. But the notion easily generalises. We can, if we like, speak of a concept of a way for $n$ things to be, for any $n \geq 1$. And if what makes for concepthood is a pedigree, extraction from what represents something as being something, we might equally well take $n \geq 0$. For the bottle to be on ice is a way for things (the mass) to be. There is no harm in speaking, accordingly, of the concept of the bottle being on ice (alternatively, of things so being).

This notion of a concept comes in order of logical priority, and what it is of in order of ontological priority, after the notion of a proper predicative subthought, thus, by transitivity, after the notion of a whole thought. Though it is not Frege's mature notion, it contains what for Frege is most crucial to the work for which concepts are wanted: for drawing that distinction underlying Frege's first and most fundamental contribution to logic. Frege writes of this in 1882:

Still more important, it seems to me, is the distinction between an individual thing (Einzeln) and a concept. ... The relation of subordination of one concept to another is entirely different from that of the falling of an individual thing under a concept. One has, so it appears, followed too closely the linguistic scheme of subject and predicate, despite the fact that this spans two entirely different logical relations. (1882: 118)

For the distinction between these logical relations to come into view, the idea is, we need something on the right side of the representing-as relation which relates to the items it identifies in a fundamentally different way from that in which a proper name relates to what it names. In this essay, the name 'Frege' functions as a proper name. It names Frege, creator of two Begriffsschriften. But for a happy occurrence some time in February 1848, there would have been no Frege, thus nothing for such a proper name to name. In which case there would not even have been such a proper name (nor any 
thoughts of Frege.) Just here a concept must differ in re falling under. Had Sid not existed, the world would have been one lager-lover the poorer. The concept of being a lager-lover might have been the same for all that. As it would have been, he existing as he does, had he developed a taste for chardonnay, or, seeing bliss to need company, joined Pia in her rounds of Billecart-Salmon. What here is constant in a concept is, not (in general) what falls under it, but rather its demands on so falling; what, by it, such might be. (A concept of being that very one, Sid, depends on Sid for its existence, and on there being the demands for falling under it that it imposes. Of course these are satisfied precisely where satisfied by Sid. Would it still be Sid who once loved lager but now takes only tea? Whether such could be depends on the sort of thing Sid is to be taken to be.)

\section{Objects (beyond Collidables)}

On our present approach, the most general notion of an object ought to be fixed in terms of the role of an object in the business per se of being true, just as with our present notion of a concept. The core idea here is simple: an object is whatever can combine with a concept (more precisely, what a concept is of) to form a way for things (the mass) to be; a way it takes a whole thought to represent things, thus a way for truth outright to turn on how things are. It is thus something of which a proper predicative subthought might predicate.

In 1891 (having made concepts functions) Frege wrote,

The question now arises what is here being called an object. A textbook definition I take to be impossible because we have to do here with something which, on account of its simplicity, does not admit of logical analysis. It is only possible to gesture at what is meant. Here one can only say in brief: an object is anything which is not a function, thus whose expression carries with it no empty place. (1891: 18)

With Frege we will eschew textbook definitions. But Frege appears here to be thinking categorially: there is a certain sort of thing, The Function; (roughly) all else is an object. Here we part company. To retrace steps, a proper predicative subthought is that which plays a certain role in a decomposition of a whole thought. A concept is that which is fit to combine with the feature of representing-as to form such a subthought, that is, to play that role. Fitness for role here requires generalising, in a proprietary way, over particular cases, capturing some and/or rejecting others. Here one may distinguish between what is so fit, what not: some things, such as Sid or one of his big toes, are absolutely unfit for purpose; others are absolutely fit. So we have something like a categorial distinction: there are those items fit for the role, and then those others not. An object, to logic's eye, is whatever is fit to play a certain role as just set out above. To be an object is to be fit for this role. But it is not clear that this demand identifies a category of items- the ones so fit as opposed to others not-much less one disjoint from that of concept. Pro tem we will take the notion object to determine, rather, a status, namely, objecthood, to be enjoyed. 
Collidables are absolutely unfit for a concept's work. Collidable is categorial. Even in philosophy, when we bandy the word 'object' about it is hard not to take collidables as our model. But if object is to be construed in terms of logic's needs then the realm of objects (if realm it is) extends much farther, all the more if we depart from Erdmann (whose would-be objects, Vorstellungen (ideas), are precisely unfit for this role). The question whether objects form a category, or whether object is just a status now becomes urgent.

If generality is a concept's sine qua non, what is an object's? Again we may turn to Frege:

By the Sinn of a proper name ... its Bedeutung, where there is one, is only illuminated (beleuchtet) from one side. It would be part of a comprehensive knowledge of the Bedeutung that for any given Sinn we could say immediately whether it has this Bedeutung. We never attain to this. (1892: 27)

It is intrinsic to an object (or, better, to objecthood) that it is vielseitig beleuchtbarilluminable from indefinitely many different sides; that it has a career of indefinitely many slices. What is intrinsic, that is, is its capacity to recur. A collidable recurs in our shared environment. That disheveled character staggering out of Der Alte Schnorrer as we made our way in around preprandial hour the other day may be (or not) that very rather dapper chap at the vernissage today, sipping delicately from his flute of BillecartSalmon. A collidable, as it might be put, leaves an unbounded footprint in the world, is liable to make its presence (or absence) known in an unbounded variety of ways. Reaching beyond the collidable, an object has an unbounded capacity to recur in thought, and specifically in thoughts. It is, intrinsically, something liable to be (or not) $a$ way for a thing to be, that first ' $\mathrm{a}$ ' indicating indefinitely.

Which answers our question. There is an object (something fit for that role) just where there are enough answers to questions whether something is that one. An object, thus, is what has a profile, or distribution, in the relation of identity. Allowing for such participation, that is, for answers to such questions, is a concept's work. For each Beleuchtung of an object, there is a particular case, the thus-beleuchtete being as it is. For that Beleuchtung to be of Sid is for that particular case to instance a certain concept: the one of being that very one, Sid. (Vide Frege 1919: 116) So we may say: there is an object just where there is a concept of being that very one. Such is the sine qua non for playing an object's role. With which it becomes an open question object is a determinate category.

A concept of an object is, to be sure, a special case: no Sid, no concept thereof. The aloofness concepts were wanted for may now seem threatened. Here we need the distinction between falling under and instancing. Trivially, only Sid could fall under a concept of being Sid. But Sid's being as he was that evening at Der Alte Schnorrer and his being as he later was at the vernissage, are two different particular cases of an object's being as it is/was. Neither need have occurred. The concept of being Sid would have been the same for all that.

Sid is a collidable. As Frege notes, there is no intrinsic connection between objectivity, thus between objects, and collidability. One feature of Sid's case which generalises, though, is this: just as Sid does not auto-individuate (we look not to him, 
but to the concept of being him, for answers to the question what might so count), so, too, for any object. The second is the unboundedness of an object's beleuchtbarkeit: its capacity for making its presence known, thus for making itself identifiable. To see this in the general case one needs the distinction between falling under and instancing.

What is ruled out as a candidate for objecthood here is precisely what for Erdmann would be the central case: something 'all in the head', a Vorstellung in what Frege calls the psychological sense: what requires a bearer (must belong to the contents of someone's consciousness) and brooks no two. Here are two ways of saying why this needs to be ruled out. First, suppose that some object were a Vorstellung. So for it to be the object it is would be, eo ipso, for it to belong to the psyche of a given thinker. It could have no career outwith that Psyche, would be beleuchtbar in no other way but as that in which it is beleuchtet in that presence, thus to that thinker.

But such proprietorship now infects any thought of that object that it is thus and so. For the only Beleuchtung a thought could exploit to make itself about that object would be one by which the Vorstellung was beleuchtet for its proprietor alone. So for it to be that thought would be for it eo ipso so to relate to that proprietor. But being proprietary to so-and-so's psyche cannot be an individuating, or intrinsic, feature of a thought, a condition on its occurrence (e.g., in someone's thinking). So nor could a thought be thus proprietary. (Cf. Frege 1897: 146) For such status fixes no determinate way for truth to turn (in part or whole) on how things are, as (as we have seen) it is intrinsic to any individuating feature of a thought to do. The feature of being linked to a particular psyche as just sketched would thus be in the same boat as that of being coloured blue, or being square, or, like a setting sun, sinking slowly into the sea, when it came to individuating thoughts. If a thought is just that by which truth can come into question at all, then none of these can be an individuating feature of a thought. So a thought could not be singular with respect to a Vorstellung (such that for it to be true was eo ipso for it to be true of that). So a Vorstellung could not play the role of object in the logikgemäss sense of object.

Frege tells us, "By the step with which I win myself an environment I expose myself to liability to error." (1918: 73) A thinker's liability to error in re such-and-such is just a form of the hallmark of objectivity: the distinction between something's being so and it's being taken for so by no matter who, no matter where or when.

If Erdmann is right as to 'what's just in the head', then the (logikgemäss) notion of an object, generalising as it does away from collidables, cannot get started. But then neither can the notion object. What lacked that generality Erdmann makes unachievable would not be logikgemäss, injecting into logic itself a topic-specificity which is foreign to it and inimical to its existence. Logic's concern with objects is with their capacity to recur in thoughts (Gedanken), where without distinguishing the business of Wahrsein from that of Fürwahrhalten, as Erdmann for one refuses to do, the very idea of a Gedanke is unavailable. Erdmann had better not be right.

\section{Freedom of thought}

We now have a setting for discussing our second and third questions: 'What objects are there?'; 'What is (or might be) an ontology?'. What makes these worth discussing is that there is more than just no cause to join Erdmann in his dichotomy, In the 
(spatiotemporal) environment, or 'all in the head'. A pair of such reasons is contained in the notion concept as here developed. Another in the notion object. This section considers the first member of that pair.

The first thing to note is the nature of the transition from one side to the other of the relation, _ is represented as _, and the nature of the independence of the one side from the other. It may help with issues here to refer to those notions subsumption and subordination, which appeal to the aloofness of a concept. Independence lies in that aloofness from what falls under it which any concept must maintain.

To represent-as is to subsume something under something. And the point would be: one cannot read, or analyse subsumption in terms of subordination. In subordination two generalities are related to each other: what falls under/instances the one, falls under/ instances the other. Transitions from generality to generality are just what concerns logic: a transition from one set of generalities (in the core case, a set of thoughts) to $a$ generality ( $a$ thought) may, or may not, be truth-preserving. Logic's task is to identify those transitions which would be truth-preserving merely by virtue of what being true is as such. Subsumption, by contrast, corresponds to no transition in which truth is to be preserved. The generality is all on the side of what subsumes. The subsumed need only be as it is, its so being instancing the generality. In the instancing, truth arises. But the instancer is innocent of generality, not itself liable to have instances, eo ipso not eligible for truth. The transition from left to right in the represents-as relation may thus yield, but not transmit. Truth.

Such is not to deny that what itself has generality may be treated as an object in the logikgemäss sense. For Frege himself a thought (Gedanke) is a perfectly good such object. And a thought may have truth to be preserved or not. It is party to transitions of the sort which are logic's concerns. But to predicate something of it is to make truth hostage to how that thought is, in a way to be determined by what is thus predicated of it - by when there would be a case of it — and not by what that thought predicates (of things), or when things would so be. It is that thought's being as it is which must instance, or not, the relevant way for things to be. (The two collapse, of course, where what is predicated is an identity under predication, e.g., being true. But what dictates this is what it is to predicate truth.

Freedom of Thought is one facet of the aloofness of right from left in representing-as. The idea is familiar. Suppose you are told, authoritatively, that there is a certain way for an object to be. Call this being W. Suppose you are also told, authoritatively, that Sid is one object which is that way. So now you have one case of an object being W: an object's being as Sid is is one thing which would so count. Suppose you know precisely this much and no more as to what being W would be. Now you are given complete freedom to examine Sid in any way you like. Indulge your freedom as much as you like. You will become none the wiser as to what being $\mathrm{W}$ in fact is. For now take a new particular case-perhaps Pia being as she is. There are (to understate) myriad ways for an object to be which both Sid as per first telling, and your new particular case are, and myriad ways which Sid then was, and your new case is not. Nothing you know, or could discover by examining Sid, settles which sort of way being $\mathrm{W}$ is. An instance of a generality cannot dictate how this generalises.

We now have a premiss for induction to this: Take any $\mathrm{n}$ cases of an object being $\mathrm{W}$ and any $m$ cases of an object not so being. Suppose this much and no more is given as 
to what being $\mathrm{W}$ is. Now take a novel case. There are still (at least) myriad ways for an object to be, all agreeing on those $n+m$ cases, which that new case is also a case of, and myriad ways-to-be, also so agreeing, but which that new case is not one of. We can go further. Let $\left\{\mathrm{W}^{+}\right\}$be a set of instances of being $\mathrm{W}$, and $\left\{\mathrm{W}^{-}\right\}$a set of counterinstances, neither set per se exhaustive. Now take a novel particular case. That each of our two sets contains what it does is again compatible with this novel case being of either sort.

The moral: No given extension for a way-to-be to have can, on its own, determine how that way-to-be generalises over particular cases. Suppose that $\left\{\mathrm{W}^{+}\right\}$did so. Then what we would have is not a concept (or something for one to be of), but rather a polysemous name. We would have lost just the aloofness Frege needs. Freedom of Thought is thus an intrinsic corollary of aloofness.

Such is not a case for anarchy. It is not as if a concept can generalise just any way. Concepts are in general, perhaps always, dependent on the world for their existence. As said already for singular concepts, no Frege, no thoughts about him. No whales, no thoughts about them either. Similarly thoughts about smoking (on one understanding of that verb) depend on the existence of tobacco. Nor are there thoughts about a certain metal, heavy, yellow, and malleable in its natural state, the stuff of crowns and (certain) toilet seats. Though there might have been had there been a yellow metal of which certain crowns and toilet seats were made.

There are constraints on what generalising is possible. Still, the particular case, if anything, is as it is independent of how anyone thinks it to be. It is as it is no thanks to thought about it. It is prerequisite material for thought. It is, ultimately, all there is for thought to be about: fix the particular case (or cases if you choose to articulate that far), and you have fixed everything as to how things are. And yet (Freedom of Thought), ways to think things to be float free of this. The particular case constrains, but does not determine, just how (as being what ways) it admits of being thought of. Such is no more than that aloofness logic requires.

Suppose that, with Erdmann, we reject, or ignore, Frege's idea of a third realm. We are thus left with Erdmann's options. There is the environment. But this, as just said, leaves things floating free. Only what is in the head remains to fix what yet floats free (on one or the other of those two readings of 'in the head'). But, so tasked, what now remains admissible into the head suffers from inadequacy, cannot (as we have seen) perform. The most we can now hope for is to talk as though there were a fact as to that toilet seat being gold — or perhaps only as if there were a fact as to our talking as if there were a fact as to that toilet seat being gold, etc., ad. inf..

Neglect of grammar, specifically of those two nominalisations, 'thought', is not the only thing which might encourage Erdmannism. In any event, it is worth signalling the price. It is hard to see how the first reading of 'in the head' can get off the ground. After all, empirical psychology is, for the most part, publishable (after peer review). Which means it must articulate into thoughts, things there are for one to think. But that there are really such things is just what has now been brought into question. Perhaps empirical psychology can act as though there were such things in its ersatz reports on the nature of our inclinations to act as though there were such things. On the second reading, there is really no such thing as thought, so, to quote one of our beloved, now departed, philosophers, we might as well just all go sailing. 


\section{The paradox of the intrinsic}

There is tension between aloofness and truth's austerity. It can take the form of a paradox. Aloofness in brief: what is intrinsic to a concept-what distinguishes it from any other concept - is how it decides what falls under it. So it is not essential to the concept that what instance it be just what it in fact is. Had Sid felt the charm of Billecart-Salmon, there might have been one less lager lover. Equally had he never been born. Not even a singular concept need have had all the instances it does. Sid could have stayed for the department meeting. There would never have been that case of an object's being as it is, Sid's crepuscular staggering out of Der Alte Schnorrer as he then was. It is not essential to the concept lager-lover that it should have applied to Sid. One half of the paradox.

Now for truth's austerity. The thought is that Sid drinks lager. Its truth turns precisely on whether the way Sid is is a case of an object (or someone) being a lager drinker. Such is truth's austerity: no third party allowed a role in the enterprise. So it is up to the concept alone (that of loving lager), just in being what it is, to determine whether the way Sid is qualifies as a case of this or not. But how can it do this? The concept would be just what it was, would contain the same form of aloofness from its instances, whether Sid were as he is or not, in fact whether Sid even existed or not. On the one hand, austerity seems to require something to be intrinsic to the concept lager lover: for a concept to be that one is, inter alia, for it to be fallen under by Sid's being as he then was. If not, we must look for a third party to do some of the work of his in fact so falling. But it is not intrinsic to the concept that Sid be as he then was (or, for that matter, be at all). In whatever sense this is so, it must not be intrinsic to the concept to be fallen under by just this. Otherwise, had Sid not so staggered there could be no such concept at all. (And, generalising, nor could there be once contingency is placed in the world at all.)

It might be patent that Sid is a lager lover (if ever there was). But how could this be? Suppose we looked for an explanation of how a concept, or anyway this one, could relate to such a contingently existent case as this. We might look for some principle which it is intrinsic to the concept to be governed by, perhaps one specific to this concept, or, if we are really ambitious, one belonging to concepthood as such, but, instantiated, would apply intrinsically to this one. Parallel to an idea of Emanuel Czuber about functions (vide Frege 1904), that they are governed by Gesetze der Zuordnung, we might think of the aloofness of the concept lager drinker to be governed by a Gesetz der Anwendung (a law of application).

There are notoriously two versions of this proposal. One is homophonic: the law is, a case is one of someone being a lager drinker just in case that person is a lager drinker. Let us assume (contentiously) that such is, in fact, true. It only remains to decide of cases whether they are ones of someone being a lager drinker. Clearly there is no explanation here. So suppose we decide for non-homophony (allophony?). The law would then be of a form, 'Something being as it is is a case of something being a lager drinker just in case C', where $\mathrm{C}$ is some non-homophonic condition.

Assuming that this proposed law is at least true, what it thereby accomplishes is to connect one concept, lager drinker, with others. Clearly this makes no progress in dispelling the initial worry. The worry was: How could it be intrinsic to something, A, to dictate the status of something, B, where it is not intrinsic to A that B should so much 
as exist? Such would be like a singular thought dictating that an object is to be the one it is about just in case that object is $\mathrm{G}$, independent of whether there is such an object as $\mathrm{G}$ of which to dictate. This worry arises equally for that supposed condition $\mathrm{C}$ as it does for lager drinker. Thus, nothing has yet been done to dispel it.

One lesson to be learned from all this is the following: relations between concepts cannot as such determine how those concepts relate to what there is to fall under, or what there is to instance, them. Correlatively, relations between predicative subthoughts cannot on their own determine of what such a subthought would be true. More is required if there is to be an instancing relation, hence if truth is to be yielded, at all.

In all this there is a second lesson. Suppose one wanted an entirely general theory of the phenomenon of instancing, or even of the instancing of some one concept, such as lager drinker. The theory would be given the task of filling in that 'more' which is left out merely by connecting one concept with others. Such an ambition would run up against the limits of theory-receptivity. The need here for an answer to say something beyond just how one concept relates to others points to why such limits pose difficulties unlikely to be surmountable.

Clearly, for at least many of the concepts we grasp, we have unlimited capacities to recognise instancing (or counter-instancing). It is not that it is inherently and incorrigibly problematic whether someone counts as a lager drinker. If it were, we would have no concepts. A general theory of such a capacity in a thinker such as us thus also runs up against the bounds of theory-receptivity. Our capacities in these respects - and others - outrun what any theory could account for.

Aloofness was to be a way for a representer to relate to some array of objects which contrasted with a way a name relates to what it names, one in terms of which subordination might be defined (vide Frege, 1882). But for all of its aloofness, a concept must actually stand in that way to a determinate collection of objects, its extension. On the one hand, it is thus no surprise that no given set of objects which in fact fall under a concept can, just in the fact of their so doing, determine uniquely that concept's proprietary form of aloofness, thus what concept it is. (Freedom of Thought.) If they could, we would not have the wanted contrast between being what a concept fits and being what a name names. But on the other, a concept must determine its extension - in general, an extension there need not have been. But one must expect a general account of how it does so to be theory-resistant.

That all this is so would neither surprise nor worry one who took seriously Hilary Putnam's dictum, '[R]eason can transcend whatever it can survey' (1988: 119), nor his unfoldings of that idea through a long series of examples throughout his career. Nor would it surprise one who had taken Descartes' version of that same point (1637: 9092) on board. Nor would it worry one who looked even a bit closely at the sort of task a serious psychologist undertakes. A psychologist is, as a rule, fastidious (and studious) as to the modesty of his ambitions, taking care to remain within the bounds of theoryreceptivity (as Frege took great care to remain in such bounds in choosing what topic logic was to be).

A psychologist might, for example, approach the question how one human being might be able to recognise another, even after long absence, even after great changes in appearance. The psychologist might note that often someone is recognisable to us by his face. How, then, is a person's face recognise as his? The question may set off a search for visual features of faces abstract enough to withstand the usual 
transformations (e.g., ageing), but concrete enough to be, jointly, proprietary to a given face, and to which humans are in fact sensitive. How does this stand towards the original question? Suppose that (better things for better living through chemistry) faces came to be, typically, considerably more plastic than they in fact are. Or suppose weekly face-transplants became the norm. Then the psychologists theory would no longer hold. Suppose that, for all of the ways one person's face may now vary from one occasion to another, it was still possible to recognise a person by his face in some way unanticipated by the psychologist. Then his theory would not account for this. For all of which the psychologist might remain unperturbed. Explaining what would be recognisable to a human under such circumstances was never part of his bargain.

As Charcot put it, 'La Théorie, c'est bonne, mais ça n'empeche pas d'exister.' Achievable theories must be modest. Suppose the psychologist's initial questions provoked an attempt at an unbridled theory, a theory of the most general case, accounting for absolutely any possible case in which one human might be able to recognise another, or to do so by his face. One should not expect there to be such a theory. One who doubts this should read his Descartes and his Putnam. Anyway, such a theory would not correspond to what scientists, in their proper modesty, in fact undertake to do.

In serious science ambition $i$ bridled. Serious scientists pay serious attention to just how to bridle it in order to remain within the bounds of receptivity to theory. Frege paid a great deal of attention to this. Just this led him to his notion Gedanke. That there is no general theory of aloofness, or even a single case thereof, need not mean that we will be left at a loss when confronted with cases. One who finds mysticism in this might well follow Putnam closely in his tracing the structure of how difficult such cases are in fact dealt with.

No limits are set, or set fast, on what might bear, in a given case, on whether someone was a lager drinker. And in a given case multiple factors are liable to bear, some one way, others the other. Suppose Sid drinks lager by choice, but inveterate selfflagellator that he is, often deprives himself, drinking G\&Ts instead. At what point does the way he is cease to be a case of being a lager drinker? Must this question have an answer? If it did not, could not that, too, be part of what one would be able to recognise in grasping what being a lager drinker is? Perhaps if objects were fleeting enough, such inconveniences could not arise. Russell tried out that idea around 1918. But the fleetingness of his objects bought for him nothing to think about at all. (Travis, C., Frege: The Pure Business of Being True, unpublished) One might also try to skirt the issue here by postulating a magic ingredient in instancing, call it 'the Ferndoc Factor'. Best find it in a pair. A pair $<$ (concept), (particular case) $>$ might be, as it were, full of Ferndoc, or bereft of such (or in conditions in between). What makes the way Sid is a case of someone being a lager drinker is that it and that concept form a pair rich in Ferndoc. As for what Ferndoc is, well, you know, don't you? You encounter it all the time. As for saying what it is, well, maybe someday. But at the dawn of that day, being Ferndoc-rich will become a concept like any other.

One Erdmannian enough might think at this point: if concepts are not reducible to something else, they can only be 'all in the head'. So reducible after all: Whether being as Sid is is a case of being a lager drinker is decided by what we, or relevant ones of us, are inclined to say. And when is something what 'we' are inclined to say? Such 'more help' is no help. Better not to ignore Frege's distinction between the psychological and the logical, between being true and holding true. 


\section{The reach of Objecthood}

There are ways for things (mass) to be, and there are ways for $a$ thing to be. Where one of these first is instanced, the question 'By what?' is otiose or worse. 'By whatever might' is answer enough. Where one of these second is instanced, the question 'By what?' is always cogent. An object's mission is to be an answer to such questions (whether true or false). To be fit for mission is to attain to objecthood. But, we have seen, to be fit for mission is to participate in the relation of identity, that is, for there to be answers to indefinitely many question of an object whether it is this one. Where the wily fox of Austerlitz may or may not be the loser of Waterloo depending on how those two career-slices are linked, there we have objecthood. Suppose objecthood requires no more than this. Then, speaking categorially (and accordingly misleadingly) there are objects galore, way more than you could shake a stick at. Too many, in fact, to have a number. This last can be put another way: There can be no such thing as 'the totality of objects'; no domain could claim that title. Quantifiers must be understood accordingly; not that it is straightforward what 'accordingly' would be, but at least 'any' by preference to 'all' or 'every'. The first thing here is to say why this should be so. We might thus gain insight into what might move one to join Erdmann, or us, in re objecthood.

An example. Reviewing his oeuvre to date, Sid sees it deficient in quotability. His claim on posterity will have to be staked elsewhere. Inspired by Bentham, he thus arranges that, post last breath, he should be preserved, dressed in his favourite track suit, and, Seidl in hand (refreshed twice daily), be sat at his usual seat at the Stammtisch of Der Alte Schnorrer, in perpetuity. If not by text, by gesture.

Suppose we now ask whether this new fixture at the Stammtisch is Sid. I would find it natural not to know quite what to say. I recognise that some would want off the boat at just that point. I can only beg their indulgence pro tem. Anyway, those of us who do not know quite what to say, or, still stronger, who take there to be no saying, might then also be inclined to say something like this: 'Sid (or perhaps better being Sid) may (not incorrectly) be understood, or taken, to be something such that that denizen of the Stammtisch is Sid (alternatively, a case of something being Sid), but also such that that denizen is not Sid (alternatively, being as it is is not a case of something being Sid). What it would be as such for an object to be Sid (that very one) leaves the matter open-admits of both understandings.

Our ability to say such things may be challenged along following lines. If being Sid may be understood so that that denizen of the Stammtisch so counts, let us so understand it. When I am speaking of Sid on that understanding as to who I thus speak of, I will signal this by writing ' $\alpha$-Sid'. When speaking on an understanding on which that denizen is not Sid, I will write $\beta$-Sid. Now, when I write ' $\alpha$-Sid', it is Sid who I am understanding to be there at the Stammtisch. That is, put materially, $\alpha$-Sid is (that very one) Sid. But mutatis mutandis when I write ' $\beta$-Sid'. So, speaking materially, Sid is $\beta$ Sid. By transitivity, $\alpha$-Sid is (that very one) $\beta$-Sid. But this contradicts Leibniz' law, for $\alpha$-Sid is something which $\beta$-Sid could not be.

When we (philosophers) ask whether that newly arranged presence at the Stammtisch is Sid, what we want to know is not which of 2 or 3 different objects Sid is - whether the one which survives embalming, the one which does not, or the (or a) one for which such is not decided. Such is not the form our question takes. That is the 
moral of the argument. When Max (another Stammkunde) first encounters that newly arranged placeholder, he might also ask, 'Is that Sid?', what does he want to know? Probably not whether Sid is really $\alpha$-Sid or $\beta$-Sid. If this is his first encounter with the embalmers masterpiece, and speaking on the $\alpha$-understanding of being Sid, he might just want to know whether, so speaking, this is Sid. Is this what has become of him? And all goes well so long as all concerned keep speaking on that understanding. Attribute to Sid, so speaking, something which would be so of him only on the $\beta$ understanding, and you have problems. One must choose (and be saddled with the choice). But also, one may choose.

There can be intelligible questions which of several objects such-and-such is. As we approach Der Alte Schnorrer at the usual crepuscular hour, we see a shadowy figure staggering down the street. Is that Sid? Or again, someone says, 'Sid's question floored Benno.' There being many 'Sid's in our circle, we might ask which 'Sid' is meant. The answers to these questions are simply matters of fact. From behind, collar pulled up against the wind, under a woolly hat, Sid may be a bit hard to identify. Give us further facts about that retreating form and our question is answered. Or, in the second case, 'By 'Sid' I mean Pia's burden' may do. Questions whether it was Sid or someone else who ... are not usually ones as to which of several persons Sid is.

Our (philosopher's) question is of a different order. The key difference is that it involves a notion of an understanding. It is about something Sid might be understood to be or not, or, better, about what being Sid is to be understood to come to. If that shadowy retreating figure might or might not be Sid, the problem is not usually that it might or might not be depending on what you take being Sid to be. One only needs a clearer look. For the philosopher, though, this first precisely is the problem. One thing to ask, then, is just what it is that might bear an understanding. One might then observe that an object, or what plays that role, is the wrong sort of thing for this. Occasion for bearing, or assigning, an understanding arises along with generality. It is what generalises which might be understood to do so in one way or another. As per preceding, there is an object just where there is a concept of being it. The object does not generalise, or certainly not over instances of itself. But a concept of being it (that very one) does. In any given case, one might ask how it does. Which can be construed as a question of how it is to be understood. So what we need to look at here is not Sid (paunch and all), but rather being Sid, or, expanded, the concept for an object to be that very one, Sid. One has an object to think about only given that choice of concept, or understanding, has been made.

Questions what to count as something being Sid rarely arise. There are rarely choices to make. It would be a surprise, perhaps, if that rather dapper chap delicately sipping from a champagne flute were Sid. But had Max watched the doings down the spa (from t-shirt to cravat and blazer) he would not have been left wondering whether to count this as Sid. An object may be presented to Max in such a way that it is impossible to tell whether this is Sid or not. Such answer must be found in how one Beleuchtung relates to another.

The philosopher's question is as to what would count as what. We assume as much as needed as to what happened in the transition from last breath to Stammisch presence. The question is when it would be Sid at transition's end. It is as to this that we find room for various views, or understandings, which is also room for recognising that what would be Sid's (non-living) presence on one such understanding would not be 
on another - and that what it would be for something to be Sid, in so far as such is fixed full stop, does not decide between these (admits of both).

Of course, for any two objects at most one can be Sid. So where there counts as being two distinct things (defunct Sid and stuffed Sid, as it were) where the one is to be understood to be Sid, the other must not be. So, though each of such a pair of understandings may be admissible, the pair are not jointly admissible: one cannot have both at once. Our philosophical questions must preserve such proprieties as do, unproblematically, those more ordinary questions just scouted. If there is such a thing as being Sid, then there is a certain object, Sid. But then, for any pair of objects, A and $\mathrm{B}$, one cannot say of Sid that he would be the one object on one understanding, the other on another. Where one says: on one understanding of being Sid he survived, on another he is defunct, part of this bargain is that it is yet undecided, or at least unknown, how in this domain objects are to be counted. One could also say: what domain is in question.

Observing the Stammtisch and knowing the facts, we might say: things might now be understood to be such that Sid is at the Stammtisch, or they might be understood to be such that he is not. True, however you look at it, there is some object in that place at the Stammtisch, embalmed, etc. But (for present purpose) it has not yet been said what object this is. On one understanding as to what it is we thus encounter, the answer to that question would be, 'It's Sid'. On another it would not. This is not yet to say that at the Stammtisch there is an object which would be Sid on one understanding of what so being would be, not on another. To speak of such-and-such object being Sid or not enough must first be understood as to what being Sid would be for the question to become simply factual, one as to what career a given object in fact enjoyed.

Identity is here unlike, say, being a lager drinker. Whether Sid's degree of devotion to that pastime counts as being one may depend on what one understands by lager drinker. It need not depend on what one would understand by being Sid. In re matters at the Stammtisch, what calls for understandings precisely is what it would be for an object to be Sid. Where, in the first case, bereft of adequate understandings, we may be unable to count up lager drinkers in the room, in the second what we do not yet know how to count are simply objects in the room (or relevant domain). In both cases there is what we can, and cannot, yet say. The difference between them is no more than one would expect the difference to be between a singular concept, one of being that very one, so-and-so, and one whose extension, on the contrary, might perfectly well be other than it is.

Having a paunch is a way for something to be. So, too, for being that very thing, Sid. When something would count as being that way is, in both cases, liable to be an occasion-sensitive matter, posing questions the answer to which depends on such things as why, when or where they are being asked. In the second case, this means, eo ipso, that what objects there are is also an occasion-sensitive matter in this sense. The point fits into another setting.

An object (pleonastically a countable) is a partial articulation of a mass, of a sort suitable for that role in representing-as discussed above. For this role what is paramount is its capacity to recur: what it is to combine with is a way for $a$ thing to be, thing indeterminately indicated. Thus objecthood's ground in identity. Thus is there an object only where there is a concept. The concept's role is to group together Beleuchtungen, that is, different slices, each of the career of some object, into Beleuchtungen of the 
same thing. Any coherent way of doing so gives us a concept of an object, subject again to those bars to having all objects at once. In imagery, just as cutting the cheese in slices precludes cutting it in blocks (marriages have ended on less), so carving out objects in one way (from the unarticulated mass, things) may preclude doing so in others. Thus, there can be no such thing as 'the totality of objects', or 'the domain/realm of all objects'.

In Grundgesetze, notoriously, quantification (such as it is) is unrestricted. This means: there are no means within Grundgesetze for imposing on quantification a restriction to a domain, nothing which restricted quantification would look like within Grundgesetze's expressive means. But this only shows something about what is involved in applying logic to some (generally topic-specific) realm of discourse. Choice of a domain over which to quantify belongs to choice of that to which logic is to be applied in a given instance of its application. All such work is presupposed as done before we get around to providing logic's laws with something to engage with. (Travis, C., Frege: The Pure Business of Being True, unpublished)

What is it to have such choices to make (at whatever stage of the game)? For Erdmann, this could only mean: there being the objects there are (or any given domain of such) is really all just 'in the head'. That is, apart from our thinking there is really no such thing as there being such-and-such objects. Such is certainly not Frege's view, nor need it be ours, at least on grounds of the above. To put the point in the simplest way, when the verb 'think' is nominalised into a noun, 'thought', the nominalisation may be, for all that, into two different such nouns. One such noun speaks of the phenomenon of thinking, a certain activity carried out, or engaged in, by thinkers. To this belongs such things as 'grasping' thoughts, thinking them, or expressing them. The other such noun speaks of the objects of such activity, that which may be thought or expressed. In John McDowell's helpful term, it concerns thinkables.

The point of Frege's distinction between the logical and the psychological is to separate out this last phenomenon, centrally the business as such of being true, from the first, to study it as a pure phenomenon entirely on its own. That there are such and such concepts of objects to be formed by the route mentioned at the start of this essay, that a coherent set of thoughts can exploit only a subpart of the possibilities here at once-all that belongs to the phenomenon of thought, second nominalisation, is independent of those doings which make up the topic of the first. This second phenomenon is certainly not located in the head (nor located anywhere). It is as it is independent of how it is thought of. In philosophy, it seems, there has always been resistance to this idea. But such resistance, so far as rational, must be for reasons other than anything discussed here. And it is best made, if at all, in full awareness of the price: certainly no less than loss of anything to be grasped at all.

\section{An ontology of One's own}

Things (the mass) does not auto-articulate into things (countables). When the call is for objects, there are indefinitely many ways to generalise over occurrences thus to identify and capture cases of the same thing twice. Such generalising is, to be sure, constrained by the way things are. Logic, e.g., precludes the same thing from both occurring and not in any given instance. Facts preclude such a thing as 'being of the same genus as the 
unicorn', or 'having made a pact with the devil'. Still, by Freedom of Thought the way things are leaves indefinitely many careers - assemblages of occurrences-for an object to have. There are thus more things articulable from the way things are than one could ever get in mind, though subject to the restriction that not all articulations can be performed at once (recall carving cheeses). We cannot articulate things both into a certain object, the very one which A, and also the very one which B, and into an object, the very one which A but not one which B. But we might be able to do either at expense of the other.

That the mass, things (being as they are) does not auto-articulate is just a special case of Freedom of Thought, itself just the idea that what generalises as does a way-to-be, admitting of an indefinitely extensive range of cases of something so being and/or of something not, cannot be identified as the general thing it is merely by any given determinate extension it might be assigned. Generalising in this way, as Frege insisted to Marty (or Stumpf) in 1882, does not reduce to naming. So the mass is articulable in multiple diverse, sometimes mutually exclusive, ways. It does not follow that when it has been articulated in a given way, e.g., into Sid's refrigerator-something of which to predicate indefinitely many things - that articulate, the refrigerator, is not 'really' to be found in the way things are, so that, e.g., that Sid's refrigerator contains mayonnaise is not really among the ways things are, casu quo are not.

We turn now to ontology. Ontology pur sang as I will call it has as its topic what there is. Insofar as it is a topic for philosophy, its concern will be with the most general (non-topic-specific) things there are to say as to what there is; with the most general sorts of things there are and their interrelations. It is not guaranteed that there will be very much interesting to say on this topic. But Frege tells us at least two or three things of interest for present purpose. First, there are objects, and also ways for them to be (ways they may be represented as being), thus generalities. There are objects (in logikgemäss sense) if there is to be truth preservation. And there is truth preservation (and its absence) if there is such a thing as the business of being true, thus if there are truths and falsehoods at all. This is so because truth preservation depends on samenesses between potential truths and falsehoods, samenesses identified in decomposing such items (what Frege terms Gedanken). Any decomposition, Frege tells us, has at least one element in the same business as the whole Gedanke, to wit, representing-as. A central sort of sameness will then be predicating of the same thing twice. Thus there are objects if there are countable items to stand in logical relations, thus if there is to be a business of being true at all.

Second, there are external objects if 'external' means mind-independent, that is, ones encounters, or acquaintance, with which are not restricted to any given thinker (or thinkers). Such is a necessary condition on the required capacity of an object to recur. (I here omit argument, but see Travis, C., Frege: The Pure Business of Being True, unpublished, chapter 4.) Must at least some external objects in this sense be in space and time? Such may or may not be part of the business of being true as such. In any case, beyond this point, space opens up for the world to speak as to what there is and what not. At which point there cease to be questions on which for philosophy to render verdict. At which point, renouncing topic-neutrality, we descend from our highest level of generality.

As said already, it was not promised that ontology pur sang would be exciting. It can be made to look more exciting if we inject some spurious assumptions. Notably about 
the nature of objecthood - e.g., that there must be something spatiotemporal about an object, or that the only real objects of experience are mind-dependent, or what one could not but be experiencing given that things seemed as they did, or that the only things there are are things one absolutely cannot get away with denying that there are. It is a long and tortuous route back from such spurious assumptions to common sense. The number of trees felled and amount of ink spilled, on working one's way back - and the dismal results thereof - might well spook a level-headed philosopher away from the topic altogether.

It might help here to note that while there may be little more to say as to what ontology pur sang must contain, Frege shows us at least one thing there is to say as to what it might contain. Here is one way to put it. There is an object just where there is something with the requisite capacity to recur. Put another way, there is an object just where there is a generality, a way for a thing to be (or concept thereof), namely, being that very object such-and-such, e.g., the victor at Austerlitz. For there to be such a way for a thing to be is for it to be determinate, often enough, when, or where, a thing's being as it was would be a case of it being, casu quo not being, that way. There is an object, Frege tells us, just where there would be sufficient answers to such questions were there such object. The just here is what counts. This much is required and no more. Any extra requirement on objecthood is per se spurious. Applying this tool may help make ontology pur sang at least somewhat less spooky.

The reason for the modifier 'pur sang' above is to distinguish a certain philosophical topic from two other notions ontology. Each of these speaks of an ontology and assigns this an owner. In the one case the notion is of the ontology of a theory, in the other of a person, or personification, e.g., Sid, or The Plain Man. Each of these differs from the other, and from ontology pur sang in its role, and thus in its commitments.

The notion of a theory's ontology can be explained thus: The first task of a theory of a phenomenon - whether motion, or truth-preservation, or German syntax — is to identify that in the phenomenon which exhibits, or participates in law-like behaviour, at least at what the theory treats as the fundamental level. A theory of motion, for example, might thus include such things as force, mass and velocity in its ontology. A logic might include such things as predicative or designative subthoughts, or logical forms in its. (For Frege the fundamental level of law-like behaviour here is that of truth values and functions from objects into these.) The theory then states (or aims to state) the laws which govern this presumably law-like behaviour in terms of the items in its ontology. Note that the theory's ontology is not an inventory of what, according to the theory, exists. It is an inventory of the theory's proposed protagonists in the law-like behaviour it seeks to describe. It is highly unlikely that there is a basic law of mechanics to the effect that when a force of degree $\mathrm{F}$ is applied to a body which contains a quantity $\mathrm{M}$ of mayonnaise that body will accelerate at rate A. So mayonnaise is unlikely to appear in a mechanics' ontology. This does not mean that mechanics tells us that there is no such thing as mayonnaise. Mechanics does not venture to say what there is tout court.

I will call an ontology with a personal or personified owner a bespoke ontology. It contains its owner's commitments as to what there is. Rendering someone's commitment as to what there is in terms of some set of countables is a daunting task, to understate. But for what follows I will suppose the following ideas to be in force. First, one way to make, or exhibit, a given such commitment is just to talk in the normal way. If Pia (knowing that mayonnaise is funest for wine) asks, 'Is there mayonnaise in the celeriac?', she thereby 
purports to be speaking of mayonnaise and of (a certain dish of) celeriac, and thus to there being such things as (being) mayonnaise, celeriac, and so on. Similarly if Sid tells Benno that Pia keeps a fine collection of runcibles at Genezeverdonk. (A bespoke ontology may commit to containing what there is not, e.g., such a thing as being a 'runcible'.) Second, I will assume that a bespoke ontology contains both commitments as to what there is and commitments as to what there is not, in both cases rightly or mistakenly. (One may admit, or refuse to admit, things into his ontology.)

Any bespoke ontology is committed to whatever belongs to ontology pur sang, that is, to the most general conditions on answers to questions what there is. What is (usually) of interest in a bespoke ontology is that by which one such may differ from another; more worldly commitments at a less general level of generality as to the way things happen to be, e.g., as to whether there are such things as emulsions, or whether, in particular, there is such a thing as mayonnaise. For one to commit to there being such a thing as an emulsion it must first be fixed sufficiently well what it would be for there so to be. As things stand, such is largely a task for chemistry. Similarly, committing to there being such a thing as mayonnaise presupposes sufficient determination of what it would be for there to be such a thing as mayonnaise. So far as we know, being an emulsion has a role to play in this, though some sense can be made of the idea of mayonnaise not, or not always, being an emulsion. What is common to both cases is that in each what makes such commitment intelligible also provides ways for there to be an answer to whether there really is such a thing to be committed to or not. Prima facie, a bespoke ontology, or its owner, aims to represent things as no other than they are, both in its inclusions and in its omissions. So it does insofar as there is such a thing to be done. An idealist might embrace that caveat, denying there to be such a thing. But the structure just discerned in the business of bespoke ontology is a major obstacle to such an idealist being right.

One sort of recoil from the idea of ontology pur sang, or anyway its vicissitudes suffered by spurious assumptions, is exhibited by Quine in a 1981 essay which begins thus:

Our talk of external things, our very notion of things, is just a conceptual apparatus that helps us to foresee and control the triggering of our sensory receptors. [The triggering, first and last, is all we have to go on.] ...

... [S]cience is a conceptual bridge of our own making, linking sensory stimulation to sensory stimulation; there is no extrasensory perception. (Quine 1981: 1)

There are two things in the first sentence to bring one up short. The first is the reference to 'sensory receptors' and triggerings. It is hard to imagine a theory whose fundamental level of law-like behaviour was interactions between these. (A mechanics which proposed this would be too ambitious even for a grant.) More important, though, is that it seems to contain just the sort of spurious assumption which made the sort of mess of ontology pur sang from which Quine is recoiling. One thing stands fast for Quine: there are sensory receptors and they get triggered. This much is given independent of what is doing the triggering. And it is this much, too, which it is for us to experience and, and what, we do, that is, for there to be the triggerings there are. It is 'all we have to go on', 
that is, precisely what would remain fixed no matter what the aetiologies of those triggerings, or what they might seem to bring into view. If there are really other things, and not just convenient fictions, it will have to be that these other things can be constructed out of the material already safely in hand. Quine helped himself, for no particularly good reason, to the idea that sensory receptors are 'material things'. It is this much if anything which separates him here from an idealist such as Berkeley.

The second thing is that word 'just'. Our talk of external things amounts to no more than a convenient fiction. This remark admits of two readings. On the one, the fiction would be that there are external objects at all. On this reading the remark is false, as we have seen. There is so much to ontology pur sang quite independent of any spurious assumptions it may then be saddled with. On the other reading the convenient fictions are particular things - refrigerators, celeriac, Genezeverdonk and so on. This comes up against the last-listed of Frege's contributions to ontology pur sang, to wit, his bar against spurious assumptions: objecthood only requires a certain sort of recurrability, in thoughts and in things. If Genezeverdonk would have this given that there were such a place as Genezeverdonk, there is simply no further question as to whether there is such an object. If it would be determinate enough whether, and when, your last selfie was taken in Genezeverdonk (so to speak) then there is such a place as Genezeverdonk. It is not just a convenient fiction.

The last-quoted sentence above also evokes comment at two points. First there is the reference to 'science': 'we' (humans presumably) develop 'science' (or some of us do). There is certainly something creative about this. 'We' ('The Scientist') create structured commitments we would choose to make. We assemble the thoughts which, jointly, the theory is to be. Part of this is choosing the theory's ontology. We do not do this arbitrarily. Nor on grounds of charm or turn of phrase. 'We' aim to make the commitments which are to be made; to discover what the law-like behaviour in the relevant phenomenon is, what there is for there to be laws about. Such discovery is hard work, and not unusually misfires. It is not as if there is nothing here for such a theoretician to be right or wrong about. But in any case it remains unclear how facts about our theories' ontologies bear on 'our talk of external things', the topic of the first-cited sentence. A theory's ontology and a bespoke one serve very different ends, committing accordingly.

The second point is the talk of 'extra-sensory perception'. This sound like an oxymoron alright. But what does it show as to how Quine is conceiving things? Why might anyone think extrasensory perception might come in handy? We return to his mention of 'sensory receptors'. They are triggered, and we sense (experience sensuously). If only there were extrasensory perception, we might observe all this 'from sideways on': one might watch his receptors being triggered, and his undergoing what was thus foisted on him while, at the same time undergoing the experiencing those triggerings engendered. Perhaps then we might encounter something other than this sensuous experience (upshot of the triggerings) on which the truth of the thoughts we might think might turn. But alas! As Quine puts it, 'the triggerings are all we have to go on'. So there is nothing else for the truth of our thought to turn on. The content of our thoughts must then be constructed out of what there is for us to go on: that just-mentioned sensuousness.

Such is recognisable as just the idealist's predicament, just that which seemed to call for 'transcendental' means to get around it. (Some, controversially, read Kant this way.) All that separates Quine from such idealism is his helping himself (gratuitously) to the idea of material sensory receptors (retinas, eardrums). But as he himself stresses, this is 
neither justified nor does it help. That fantasy of viewing the aetiology of triggerings while experiencing their effects is of course nonsense. The question unaddressed is why such might ever seem called for. If it is, then since there is no such thing as answering the call, it may seem particularly important that there are many ways (if any) of being faithful to sensuous experience, identified only in terms of receptor-triggerings, none with a claim to objective priority. But this only shows the fantasy to lie in the idea of what it would take extra-sensory perception to do. The irony is that in recoiling from the dreariness of idealism in the way he does Quine falls into that very thing.

A brief comment on what in Quine's essay follows this introduction. There are two main events. First, Quine spins a tale of the bespoke ontologies he and The Plain Man in fact have. This consists part of autobiography (fitting enough considering the topic) and part of a fantasy about the aetiology of all this (as usual for a philosopher, pure Brothers Grimm). He then changes topic, identifying three cases where a theory might replace at least part of its ontology with something else. I mention just two. First, mention of integers can be exchanged for mention of one or another sort of other item, ordered as the integers are (e.g., certain nestings of sets). Second, physical objects (or rigid bodies) can be replaced by space-time points, some of which loaded with such properties as mass.

Again two comments. Perhaps the least important is this: the integers and their prospective replacements are not alternative, that is, mutually exclusive, ways of articulating the mass, things, into objects. They are not mutually exclusive at all. They can very well be held side by side. They might, e.g., stand to each other as the king in chess stands to the kings in a set of chess pieces. There is no reason why someone should not have both the integers and their replacements in his bespoke ontology.

But second, so what? Integers are replaceable by something else in statements in a theory about the relative quantities of some partaker in law-likeness which some theory or other posits. Perhaps this changes the theory's ontology. Rigid bodies are replaceable by sets of spacetime points in a theory of mechanics. This does change the theory's ontology. In both cases, as it happens, there is free choice between the two sorts of theory. That is, each may equally claim to represent things as they are. What is the bearing of this on a bespoke ontology?

Well, how do a bespoke ontology and a theory's ontology differ? The bespoke ontology represents its owner's best shot at capturing what there is (and no more) what would be captured by ontology pur sang if its aim for generality were set sufficiently low. Not that a finite being might rationally hope for full match. The aim of a theory's ontology is merely to identify relevant points of law-likeness, for any given theory, a goal fully achievable at least in principle. But suppose there were no such thing as ontology pur sang. Then a bespoke ontology could no longer be seen as a view as to what the correct ontology is - as to what there is, punkt (that now nonexistent topic). The only form of correctness left standing, for a bespoke ontology or any other, may then well seem to be whatever it is that a theory's ontology aspires to. And, if Quine is right, such aspirations are achievable (in general) in no one right way. A theory's ontology does not aspire to answer a question what there is. Nor need a bespoke ontology if there is no intelligible such question to be asked.

A diagnosis: Quine recoils from the idea of ontology pur sang, partly because of the sheer dreariness of the yield of those centuries of trying to find a way to live with idealism, and partly through misreading the significance of the fact that the mass, things, does not auto-articulate. On that misreading, due is not given to the idea thatfor all that there are alternative articulations which cannot interact with one another- 
the way things are is articulable in all those ways (and not in other would-be ones), and that it is thus that the way things are decomposes into countable ways things are, those countable part of reality no less than that of which they form part.

With which we return to our starting point. Our question was not to be what objects there are, or what it would be for something to be an object (the chopped liver problem), but rather what sort of status objecthood is. Rather than thinking of object as a category, the idea was, one might think of it as a role. Ontology would then be concerned with where, and by what, this role would be played. The role of an object is in service of a thought (something in the business of being true (or false) outright. In this role the object would join with what some proper part of the thought predicated to form a way for things (the mass) to be or not full stop. Such corresponds to the content initially assigned here to ontology pur sang. It is a perspective from which mutually exclusive candidates for the role might be held side by side without yet committing to what one would in choosing either. That 'reality' does not auto-articulate no longer threatens the idea that any articulation of it is, for all that, an articulation of it. Quine is no model for a realist. Frege, however, is.

Funding information This article was made open access with the support of King's College London.

Open Access This article is distributed under the terms of the Creative Commons Attribution 4.0 International License (http://creativecommons.org/licenses/by/4.0/), which permits unrestricted use, distribution, and reproduction in any medium, provided you give appropriate credit to the original author(s) and the source, provide a link to the Creative Commons license, and indicate if changes were made.

\section{References}

Frege, G. (1884). Grundlagen der Arithmetik. Breslau: W. Koebner.

Frege, G. (1891). Funktion und Begriff. Jena: Hermann Pohle.

Frege, G. (1892). Üeber Sinn und Bedeutung. Zeitschrift für Philosophie und philosophische Kritik, NF, 100, 25-50.

Frege, G. (1893). Grundgesetze der Arithmetik (Vol. v. 1). Jena: Hermann Pohle.

Frege, Gottlob, 1897: "Logik" in Nachgelassene Schriften, 139-163.

Frege, G. (1904). Was Ist Eine Funktion?, Festschrift Ludwig Boltzmann Gewidmet zum Sechzigsten Geburtstage (pp. 656-666). Leipzig: Johannes Ambrosius Barth.

Frege, G. (1918). Der Gedanke: Eine Logische Untersuchung. Beiträge zur Philosophie des deutschen Idealismus, 1(2), 58-77.

Frege, Gottlob, 1919: letter to Paul F. Linke, in Gottlob Freges Briefwechsel, 113-116.

Frege, G. (1882). Letter to Anton Marty (or Carl Stumpf). In Gottlob Freges Briefwechsel (pp. 117-119). Hamburg: Felix Meiner.

Frege, Gottlob, 1983: 17 Kernsätze zur Logik, in Frege: Nachgelassene Schriften, H. Hermes, F. Kambartel, F. Kaulbach, eds, Hamburg: Felix Meiner, 2nd edn. pp. 189-190.

Putnam, H. (1988). Representation and reality. Cambridge, MA: The MIT Press.

Quine, W.V.O., (1981) "Things and their place in theories," in Quine, Theories and Things, pp. 1-23, Cambridge, Mass.: Harvard University Press, reprinted in P. K. Moser and J. D. Trout, 1995: Contemporary Materialism, London: Routledge, pp. 199-215. Page references here to the reprint.

Publisher's note Springer Nature remains neutral with regard to jurisdictional claims in published maps and institutional affiliations. 